\title{
ENERVADAS, DE MME. CHRYSANTHÈME: UM SIMULACRO AUTOBIOGRÁFICO
}

\section{"ENERVADAS", BY MME. CHRYSANTHÈME: AN AUTOBIOGRAPHICAL SIMULACRUM}

\author{
Recebido: 10/05/2020 | Aprovado: 25/05/2020 | Publicado: 10/07/2020. \\ DOI: https://doi.org/10.18817/rlj.v4i1.2195
}

\author{
Mariana Fortes Maia ${ }^{1}$ \\ Orcid ID: https://orcid.org/0000-0002-5458-6700
}

\begin{abstract}
Resumo: Mme. Chrysanthème (1870-1948) foi presença recorrente nos periódicos das primeiras décadas do século XX, publicando inúmeras resenhas, crônicas e alguns romances. Entretanto, caiu em completo esquecimento: eis o destino costumeiro das mulheres escritoras que contrariavam, em alguma medida, as expectativas do público masculino. Impulsionados pela recente reedição de Enervadas (2019), destrincharemos alguns dos traços inovadores de sua obra, dentre os quais a estrutura bipartida que nos conduz a um simulacro autobiográfico seguido por um diário ficcional. Trata-se de um livro em que a protagonista, Lúcia, transforma-se em uma obra de arte, performando uma existência artificiosa que subverterá as noções de gênero. Estamos diante, portanto, de um duplo movimento: um romance, ficcional por excelência, é também ficcionalizado pela sua narradora. O corpo de Lúcia é um quadro e suas atitudes são sempre calculadas para atingir determinado efeito. Este estudo, igualmente bipartido, pensando nos gêneros que a obra pretende simular, busca compreender as motivações de tão entediada personagem que age de acordo com os postulados pela burguesia para dela debochar. Pretendemos, ainda, demonstrar a modernidade que há em suas subversões, perfeitamente coerentes com o temperamento enervado da personagem.
\end{abstract}

Palavras-chave: Chrysanthème. Diário. Autobiografia. Ficção.

Abstract: Mme. Chrysanthème (1870-1948) was a recurring presence in periodicals of the first decades of the 20th century, publishing numerous reviews, chronicles and some novels. However, she fell into complete oblivion, which is the usual fate of women writers who, to some extent, contradicted the expectations of the male audience. Driven by the recent reissue of Enervadas (2019), we aim to unravel some of the innovative features of her work, like the split structure that leads us to an autobiographical simulacrum followed by a fictional diary. It is a book in which the protagonist, Lúcia, becomes a work of art, performing an artificial existence that will subvert the diary genre. We are, therefore, facing a double movement: a novel, fictional by its own nature, is also fictionalized by its narrator. Lúcia's body is a frame and her attitudes are always calculated to achieve a certain effect. This equally bipartite study, thinking of the genres that Lúcia intends to simulate, also seeks to understand the motivations of such a bored character who acts according to the postulates by the bourgeoisie to make fun of it. We intend to demonstrate the modernity in her subversions, perfectly consistent with the character's unnerved temperament.

Keywords: Chrysanthème. Diary. Autobiography. Fiction.

\footnotetext{
${ }^{1}$ Mestranda do Programa de Pós-Graduação em Letras Vernáculas (Literatura Brasileira) da Universidade Federal do Rio de Janeiro (UFRJ). Licenciada em Letras - Português/Literaturas pela mesma instituição e Técnica-Administrativa em Educação da Universidade Federal Fluminense (UFF). E-mail: marianaforts@gmail.com
} 


\section{Mme. Chrysanthème e a modernidade}

A presença da carioca Cecília Moncorvo Bandeira de Mello Rebello de Vasconcellos na imprensa das primeiras décadas do século XX é desproporcional à frágil memória que preserva atualmente. Outrora evocada como "brilhante escritora patrícia" ${ }^{2}$, foi uma prolífica ficcionista e contribuiu ativamente com diversos periódicos de grande circulação, dentre eles $O$ Paiz, em que publicou crônicas semanais por cerca de vinte anos ${ }^{3}, A$ Imprensa, Correio Paulistano e Gazeta de Notícias. Apesar do já pomposo nome de batismo, a autora adotou o pseudônimo de Madame Chrysanthème, ou somente Chrysanthème, como sua principal assinatura. Se a grafia francesa não causa estranhamento no seio da belle époque, curiosa é a sua fonte de inspiração: Madame Chrysanthème (1887), do francês Pierre Loti, um romance de grande repercussão no momento.

A Chrysanthème de Loti é uma jovem japonesa temporariamente "desposada" por um marinheiro francês de passagem por Nagasaki. A sua fracassada função é tão somente distraí-lo com sua graciosidade, enquanto um verdadeiro bibelô. Ao fim da temporada, é deixada sem qualquer comoção:

\footnotetext{
Peguei-te para que me divertisses; talvez não tenhas tido muito sucesso, mas fizeste o que pôde: me deste o teu rostinho, tuas pequenas reverências (...). E quem sabe, talvez eu pense em ti às vezes quando lembrar deste glorioso verão, destes lindos jardins (...).

Conforme a distância entre nós aumenta, viro-me uma ou duas vezes para olhá-la novamente; mas é mera civilidade (...). (LOTI, 1908, p.216, tradução nossa):
}

Não terá a mulher que nomeia a obra qualquer fala ou menção daqui em diante: inexiste quando fora do olhar masculino. A escolha de Cecília, não aleatória, parece apontar para um projeto literário. Filha de Carmen Dolores, pseudônimo de Emília Moncorvo Bandeira de Mello, uma relevante escritora já confrontada com o rótulo de feminista, não cresce alheia às discussões de gênero de sua época. Todavia, exerce a palavra de maneira ambígua. Enquanto

\footnotetext{
${ }^{2}$ Correio Paulistano, 18 abr. de 1926.

${ }^{3}$ Maria de Lourdes de Melo Pinto (2006) estima que tenha publicado 878 crônicas somente neste periódico.
} 
jornalista, é muito crítica sobre o movimento feminista brasileiro ("para muitas das pertencentes ao sexo frágil, que quer ser forte sem discernimento e sem lógica, 0 feminismo, na nossa terra, não tem passado de uma grande e generosa permissão para tudo ousar e tudo se permitir") ${ }^{4}$, mas como ficcionista proporciona moderníssimas incursões ao ridículo masculino, ao passo em que retira o caráter ornamental e eminentemente sentimental de suas personagens femininas - as figuras trocam de lugar. Estaremos diante de artistas do cotidiano: "Suas protagonistas não agem segundo as convenções. Desfilam pelas ruas da cidade surpreendendo os transeuntes, usam o sexo como elemento de poder, aplicam-se morfina, namoram a morte e dançam o fox-trote" (GENS, 2016, p.1115). Há nestas mulheres o desejo de se estabelecerem enquanto os seres moralmente superiores que são, pois a limitada sociedade burguesa e patriarcal não poderia jamais comportá-las.

Neste trabalho, debruçaremos sobre uma das primeiras obras da autora, Enervadas, cuja publicação se deu originalmente no jornal $A$ Patria a partir de 10 de novembro de 1921, ganhando o formato de livro pela editora Leite Ribeiro, em 1922. É sua única obra reeditada nos dias atuais, pela editora Carambaia, e interessa-nos especialmente pelo seu formato incomum. Escrito integralmente na primeira pessoa gramatical, o romance divide-se em duas partes: a primeira consiste na reconstituição das memórias pregressas da protagonista Lúcia, que buscava contrariar o diagnóstico de enervação realizado por um médico, enquanto a segunda parte pretende ser um diário. Se Chrysanthème abusa de circunstâncias desgastadas pelo moribundo naturalismo, tais como a histeria e o adultério, a obra ganha trajes altamente modernos graças ao seu método de composição capaz de alcançar uma dupla dimensão artística. Lúcia, uma mulher bela, rica e criada por um pai amoroso, não se resume a uma vítima da sociedade patriarcal. A protagonista, através de sua performance corporal e de sua escritura, subverte as imposições até mesmo quando se manifesta conivente.

O objetivo deste estudo é percorrer as duas partes da obra, tendo como norte uma forte herança finissecular: o culto ao artifício. Pretende-se demonstrar a multidimensionalidade do artificial, que abrange desde a aparência, os hábitos e os relacionamentos das mulheres enervadas até a própria estrutura da obra. $\mathrm{O}$

\footnotetext{
${ }^{4}$ Revista Feminina, Ano VII, № 74, 1920.
} 
gênero autobiografia enquadra-se facilmente na premissa deste trabalho, posto ser ficcionalizado por excelência. Ainda que se pretenda honesto, passa pelo filtro do tempo, das emoções e da própria escrita. O diário, por outro lado, pretende ser o espaço em que o sujeito, supostamente distante das amarras da sociedade, despeja o seu íntimo e verdadeiro ser, discorrendo sobre um tempo muito mais imediato, ainda sob efeito das emoções. É uma busca pela eternização de um presente e um desejo pela continuidade. Entretanto, Chrysanthème consegue a rara manobra de ficcionalizar duplamente um gênero que pretende ser tão autêntico. Já Lúcia, por sua vez, produz uma autoficção ao longo de toda a sua obra - é simultaneamente a artista e a obra de arte.

Tal como a obra a que se refere, este trabalho será bipartido. A seguir, discorreremos sobre a artificialidade do cotidiano das mulheres enervadas. Confrontaremos o que a escrita das memórias pregressas de Lúcia nos fornece: uma existência em contundente estado de inebriação, sua performance corporal e um artístico itinerário amoroso. Posteriormente, nos atentaremos às pistas que Lúcia nos oferece na formulação de seu esparso diário que simula a redenção de uma mulher mal comportada através das ações de um benevolente e honrado homem que fecundará o seu ventre.

\section{As memórias pregressas de Lúcia}

\section{A estrutura autoficcional}

Chrysanthème não é pioneira ao dotar a sua protagonista de uma genealogia e de um conjunto de memórias da infância. Bem ao modo naturalista, o livro parece criar as circunstâncias necessárias para o empreendimento de um estudo de caso. Lúcia seria o laboratório: uma mulher de comportamento subversivo, histérica e adúltera. Contudo, decepciona-se o leitor que espera encontrar uma escusa no tempo e espaço em que está inserida. Lúcia está distante de corresponder a um modelo de mulher brasileira e qualquer tentativa de estudar a sua essência será sumariamente rejeitada - o seu sucesso artístico está em permanecer eternamente disfarçada. 
É evidente que a intenção de Chrysanthème não é nos convencer de que Lúcia é uma mulher real. Estamos diante de um romance que se quer aparentar autobiográfico. A verdadeira inovação não está na ficcionalização destes gêneros pela autora, mas sim pela personagem. A primeira parte do livro consiste, à rigor, em uma autobiografia escrita por Lúcia em folhas supostamente soltas: "corro à mesa, e, diante de um mimoso papel de cartas (...) principio a escrever a história da minha moléstia, que penso não ser moléstia, mas eflúvios de uma alma de mulher bem da sua época" (CHRYSANTHÈME, 2019, p.09). Como é de se esperar neste gênero, temos um narrador autodiegético. Isto quer dizer que o leitor desta espécie de texto "tenderá normalmente a subordinar as questões enunciadas a uma questão central: a configuração (ideológica, ética etc.) da entidade que protagoniza a dupla aventura de ser herói da história e responsável pela narração" (REIS \& LOPES, 1988, p.120). Estamos cientes do filtro imposto por este narrador, frequentemente agraciado com o título de "não-confiável" (LODGE, 1993). Esta é uma das principais razões pelas quais o gênero autobiográfico e seus vizinhos são ainda pouco estudados, mesmo quando o narrador alega deliberadamente corresponder a um ser humano de carne e osso. É um gênero fronteiriço entre a fiç̧ão e a realidade que acaba por não satisfazer completamente nenhum dos lados.

Um dos poucos especialistas nestes gêneros, Philippe Lejeune (2008, p.26), ressalta a importância do estabelecimento de um pacto autobiográfico, pois

diante da narrativa de aspecto autobiográfico, a tendência do leitor é, frequentemente, agir como um cão de caça, isto é, procurar as rupturas do contrato (qualquer que seja ele). Daí nasceu o mito do romance "mais verdadeiro" que a autobiografia: sempre se considera mais verdadeiro e mais profundo o que se descobriu através do texto, a despeito do autor.

O leitor tende a crer mais nas pistas encontradas na enunciação do que no enunciado. Afinal, ainda que nos comprometamos a crer em algum núcleo de veracidade dentro do discurso autobiográfico, este narrador possui um ponto de vista, de certa maneira, distorcido pela sua subjetividade. O seu texto seleciona as memórias mais convenientes e oculta o que não parece interessante aos seus propósitos. Sua narração é montada de acordo com os efeitos que deseja provocar no leitor: simpatia, compadecimento, horror... Entretanto, acredita-se 
poder alcançar a verdade através de pequenos vestígios, deixados por desatenção ou propositalmente. Lúcia pinta os seus vestígios e os distribui estrategicamente, ainda que sua intenção seja confundir o leitor, afinal, "a mentira faz parte, como se vê, da organização social de hoje. Está na massa do sangue de todos nós" (2019, p.11). Sua autoficção decorrerá deste pressuposto.

\section{O invólucro de sensações}

Lúcia busca angariar a confiança de seu leitor nas primeiras páginas de suas memórias. De entrada, nos informa ter 30 anos, ainda que só admita publicamente ter 26, e afirma sequer lembrar da cor natural de seus cabelos, "porque a moda hoje prescrevendo o simples castanho ou negro banal das tranças femininas, eu tentei, com a ajuda do henné, dar-lhes um colorido entre vermelho e preto, que atrai o olhar como uma chama velada" (2019, p.12). A henné não simula nenhum tom possivelmente natural: intensos tons acobreados sobre um fundo escuro. E, como reforçarão as repetidas menções ao seu rouge habitualmente exagerado, fica clara a sua intenção em destoar e chocar com a sua própria aparência, que é sempre pensada.

Os cosméticos e as tinturas de cabelo são frequentemente considerados mentiras em ação: "não é de se espantar, então, que se faça disso a única criação da mulher, a única via por onde ela possa chegar à arte" (DOTTINORSINI, 1996, p.65). Enquanto mulher, seria possível apenas transformar-se em um objeto de arte, sem nunca alcançar o estatuto de artista independente. Subvertendo esta noção, parece haver, em Enervadas, a tentativa de ilustrar o homem como um impossível objeto de arte e um artista muitas vezes medíocre.

Todas as mulheres apresentadas nesta obra são perversas, com exceção da doce Margarida, uma caricatura da mulher burguesa: casada, gorda, com seis filhos e sem nada relevante a dizer. O seu nome, inclusive, parece uma grande ironia em face das diversas flores do mal espalhadas por toda a parte. As outras amigas de Lúcia, por outro lado, apresentam um perfil pouco convencional: Maria Helena, uma lésbica de visual masculinizado; Laura, uma ninfomaníaca; e Magdalena, uma adicta em cocaína "de uma beleza de flor doente", responsável 
por introduzir a morfina no cotidiano de Lúcia. É possível resumir as quatro principais enervadas da obra como seres do excesso, que é

uma ideia fixa que as heroínas da literatura fin-de-siècle repetem, não sem orgulho. (...) Certamente o excesso se pode dirigir tanto para a virtude como para o pecado; mas com o Anjo em baixa, o exagero para o mal impressiona mais, e o mal é sempre o sexo. (DOTTIN-ORSINI, 1996, p.173)

Todas estas mulheres estão em permanente busca pelo gozo, sem nunca poder alcançá-lo: eis o preço pelos seus pecados. O descontentamento com a realidade acaba por conduzi-las aos paraísos artificiais, a esperança por uma nova dimensão capaz de abraçá-las. Definirá o cronista Elysio de Carvalho (2017, p.100): “A morfina (...) é um soporífico que acalma a dor e produz o sono. Nem sempre, porém, o seu abuso provém da necessidade de sedação de uma dor física. A maioria se morfiniza para encher o vazio da existência”. O estado de inebriação será uma constante dentro da obra devido à necessidade de construir uma realidade que suplante o sempre insuperável vácuo que as domina.

\section{O itinerário amoroso e moral}

O casamento de Lúcia com Júlio realiza-se através da arte. Se encontram nas noites de dança e desenvolvem um flirt que é precocemente interrompido por seu pai, ávido por saber as intenções do moço. Lúcia pondera se para a ocasião "poria um vestido claro ou um escuro? Daria à minha fisionomia uma expressão de prazer ou de doce melancolia?" (2019, p.24). O seu corpo é sempre um espaço pensado para atingir determinado efeito.

O casamento é uma instituição veementemente criticada ao longo da obra. A jovem noiva não possui qualquer expectativa sobre este momento decisivo na vida da mulher burguesa:

Todos os casamentos se assemelham e eu assistia ao meu como se fosse simples espectadora e não a primeira atriz dessa tragicomédia social. Enquanto o sacerdote, pensando talvez em outra coisa, nos induzia ao dever e à fidelidade, eu contava-lhe curiosamente as rugas do rosto fanado e perguntava a mim mesma o que entenderia do amor terrestre esse homem, a quem era proibido severamente amar como se 
deve amar na terra e como eu entendia, nesse tempo, o amor. (2019, p.30)

Reconhecendo "nesse tempo" um amor terrestre, Lúcia dá ao entender que posteriormente reconfigurará a sua noção de amor, mas isto não se dará por mera condescendência aos preceitos sociais. Lúcia não hesita em persistir na utilização de expressões como "tragicomédia social" no momento da escrita e se manterá firme em ridicularizar o matrimônio. É certo que, enquanto mulher, não poderia ela enquadrar-se nas definições baudelairianas de dândi; todavia, a sua forma de amar vai ao encontro do que preconiza o autor: "Infelizmente é bem verdade que, sem o tempo e o dinheiro, o amor não pode ser mais do que uma orgia de plebeu ou o cumprimento de um dever conjugal. Em vez da fantasia ardente ou sonhadora, torna-se uma repugnante utilidade." (BAUDELAIRE, 2006, p.48). O dinheiro não é um problema para nossa protagonista "cercada de adulações, de facilidades de vida", mas ainda assim o seu casamento possui fins meramente utilitários. Júlio sequer exerce bem o seu papel convencional de guardião do lar, sendo tão somente um parasita responsável por criar um "vácuo enorme" em sua existência. A fantasia ardente ou sonhadora urge pelo controle do corpo de Lúcia e, mais uma vez, juntando-se aos dândis, percebe-se que "esses seres não têm outra ocupação senão cultivar a ideia do belo em suas próprias pessoas, satisfazer suas paixões, sentir e pensar" (BAUDELAIRE, 2006, p.48).

Não à toa, Lúcia atribui ao seu marido um "olhar terno de lulu-dapomerânia" (2019, p.76) e considera que sua única característica marcante é a graciosidade de dançarino, femilizando-o. $O$ interesse existente entre os dois morre nos salões de dança e Lúcia não suporta o seu patético marido: "Ele nunca fora o guia de que eu precisava, o amigo que a minha solidão pedia, mas o meu inábil e inconsciente comparsa na comédia smart e fútil que representávamos e que era a corrida à exibição e às palmas de meia dúzia de doentes iguais a nós" (2019, p.44). A impossibilidade de tolerar um matrimônio convencional, sucumbindo a um profundo tédio, motivará Lúcia a buscar sensações que reanimem a sua alma: "se falo de amor a propósito do dandismo, é porque o amor é a ocupação natural dos ociosos. Mas o dândi não visa o amor como um fim em si" (BAUDELAIRE, 2006, p.48). 
Curiosamente, será o próprio Júlio, com "sua alma fútil e trepidante" (2019, p.44), quem atirará Lúcia ao seu itinerário amoroso. Para obter uma promoção, solicita que sua esposa vá até o Ministro do Exterior, Pedro Monteiro, pois este "é muito acessível a pedidos femininos" (2019, p.73). A partir de então, Lúcia experimenta uma paixão que, se efêmera, ainda é melhor do que o nada. Vivencia um conflito de consciência, simbolizado pela aparição de Padre Jerônimo (não por sua santidade, mas por configurar uma experiência inatingível e, portanto, extremamente sedutora), mas logo inaugura o seu padrão: eternamente insatisfeita, enjoa de Pedro e nunca mais torna a mencioná-lo. O mesmo ocorre com Nelson, um amigo de seu marido que, de volta ao Brasil, "surgira mais artista e menos místico" (2019, p.91). Lúcia diz querer amá-lo, pois ainda crê que seja essa a sensação suprema, mas, ainda que este affair tenha resultado em seu divórcio, não foi o suficiente para reter o seu apreço: "Nelson entrou a desagradar-me pela extrema suavidade dos seus modos e das suas músicas" (2019, p.94). Por fim, relaciona-se com Georges Dénis, um pintor francês dedicado ao nu feminino. O desafio imposto pelo semblante desinteressado do homem motiva suas investidas, mas a conquista rapidamente a enfastia. Três destes quatro homens são artistas: um dançarino, um músico e um pintor. Todos são absolutamente limitados, representantes do rudimentar gosto artístico burguês ou da manutenção de seu poder, como ilustrará Pedro.

Regressemos à figura do Padre Jerônimo, um homem que adentrou a carreira religiosa em respeito à sua amada que, na iminência de sua morte precoce, suplicou pela sua fidelidade eterna. Passou a desejá-lo ardentemente antes mesmo de conhecê-lo, devido a sua capacidade de amar tão devotadamente. Invejando a falecida, Lúcia veste-se com halos de naturalidade "Informada de sua visita, eu me vestira toda de claro e penteara os meus cabelos com mais esmero que de costume. Não pusera rouge nesse dia, e, pálida, com meus lábios na sua cor natural, eu parecia mais moça, embora menos brilhante." (2019, p.52) -, vendo no Padre a possibilidade de experimentar o desconhecido. A sua personagem não convence e, frustrada: 
moderna, sem escrúpulos exagerados, sem limites nos devaneios... Esqueci que era casada e entrei a desejar com delírio que a vida me envolvesse nas suas ondas tumultuosas e opacas. (2019, p.60)

O amor por um sarcedote não faz com que Lúcia alcance alguma transcendência espiritual. Muito pelo contrário, veste uma máscara de moça inocente com objetivos bem pouco escrupulosos: desvirtuar um padre de sua missão eclesiástica e fazê-lo trair a memória da mulher amada. A rapariga moderna não cederá lugar a uma nova Lúcia, e não seria o medíocre Roberto o impulso suficiente para tal.

Parece improvável que Lúcia tenha escrito as 91 páginas que compõem a primeira parte da obra de uma só vez, em um papel róseo, inicialmente adquirido para "enviar ao Roberto as frases de amor que me brotam da mente" (2019, p.9). Só conheceremos esta personagem masculina ao longo da segunda parte, mas é importante sinalizar a sua prévia existência. $O$ homem redentor já existe enquanto Lúcia dá voz às suas memórias mais ardentes e aos seus pensamentos mais transgressores. Ainda assim, pareceria natural que nossa autora se transformasse no momento da escrita, pois

O próprio ato de colocar por escrito a recordação que se tem de um acontecimento do passado implica em uma aproximação ou enfrentamento entre o passado da recordação e o presente da escrita. A memória tem como objetivo encontrar o tempo perdido e fixa-lo para sempre. (JOZEF, 1997, p.221)

De fato, é no meio da narrativa que Lúcia decide dar a razão ao Dr. Maceu Pedrosa. O seu passado supostamente reconfigura-se ao entrar em embate com 0 presente. Passa a dizer-se enervada sem que aparente convencida da necessidade de uma cura: "naqueles dias, eu não pensava em doença, mas sim em travar um combate à alma do padre Jerônimo, que fugiu à minha" (2019, p.65). Segue adiante alternando entre a descrição de "momentos de extrema languidez" e de "ardor excessivo", quando, subitamente, chega a conclusão de que "tudo cansa no mundo, até a liberdade demasiada" (2019, p.97). Monta uma cena verdadeiramente teatral, cobrindo o seu leito com rosas desfolhadas e chamando suas amigas para testemunhar a sua morte metafórica. A partir deste ponto, num passe de mágica, a narrativa apresentará uma nova Lúcia, ávida pelas sensações da virtude. Para o seu propósito, enquanto uma 
mulher virtuosa, é claro que precisará de um guardião - ressurge, do nada, o até então desimportante Roberto Toledo: "delicadamente, ele me retirou a seringa de Pravaz, o vidro da morfina e modificou o meu modo de encarar as cenas do mundo. Foi a seu pedido que chamei o delicioso Maceu Pedrosa e que me deixei examinar por ele" (2019, p.98). O adjetivo atribuído gratuitamente ao médico é um indício do seu projeto: a busca por sensações de toda a natureza, ainda que conflitantes. Contudo, nem todas serão alcançáveis, pelo menos não para além do seu espaço ficcional - a redenção de Lúcia é uma farsa.

\section{Memórias modernas: o pretenso diário}

\section{A estrutura subvertida}

No momento de transição entre as duas partes da obra, Lúcia promete apresentar-nos às suas "memórias modernas" (2019, p.99). Dessa vez, o adjetivo não será gratuito. Ainda que aparente ter mudado de ideia acerca do "novo papel da mulher na sociedade e no universo" (2019, p.93), o seu recado indicará exatamente o oposto. O diário potencializará a nossa desconfiança, ilustrando a capacidade da narradora de distorcer as suas palavras. Diz-se o oposto do que se pretende dizer através de uma ironia pouco caricata, capaz de confundir um leitor desatento. Estranhamente, o seu diário aparentará menos autêntico do que sua autobiografia, gênero tradicionalmente mais inclinado à ficção.

Para definir o gênero diário, partiremos dos pressupostos de Philippe Lejeune na sua obra Pacto Autobiográfico (2008). Resumidamente, o diário consiste em uma série de vestígios datados, cuja intenção é delimitar o tempo através de uma sequência de referências. O seu objetivo primeiro é arquivar em papel as memórias do diarista, construindo um fluxo temporal que busca driblar o esquecimento. $\mathrm{O}$ autor estabelece que a sua utilidade pode residir em: conservar a memória; propiciar a sobrevivência do autor pós-morte; servir como um espaço para o desabafo; promover o autoconhecimento; deliberar sobre o futuro; e resistir ao presente. Já a autobiografia, por sua vez, está concluída desde o início, encerrando-se necessariamente no momento presente, o da escrita. 
Lúcia, como é de se esperar, burla a noção de utilidade. Primeiramente, o seu diário não consta sequer de datas precisas, o que nos faz questionar de entrada a sua intenção em meramente conservar memórias e driblar o esquecimento. Dura somente seis meses, com a média de uma entrada mensal, o que contraria os hábitos diaristas. Embora não haja rígidas restrições formais acerca de um gênero tão particular, alguns outros indícios nos causam estranhamento: a presença de interlocução, a transcrição minuciosa de diálogos e a escrita simultânea de eventos, como em "Ouço passos apressados na escada, e a porta abre-se... Pouso a pena e espero meu amante que breve será meu esposo" (2019, p.148) - quão longa será a escada para que a diarista ainda espere a chegada do amante enquanto escreve esta sentença?

É questionável se, de fato, o diário sucede cronologicamente a autobiografia de Lúcia. Como vimos, na primeira parte, Roberto é mencionado de passagem no capítulo inicial, ressurgindo somente na penúltima página. Lúcia fala com certo descaso das frases de amor saídas da mente - e não do coração - que escreveria ao homem (2019, p.9). Portanto, já conhecendo-o, a escritora desenha todas as suas aventuras, negando sua enervação e explodindo na sua busca por sensações. Admite a sua patologia conforme a escrita se desenvolve, sem jamais atribuir ao homem redentor a geração de algum desejo seu pela cura. Muito pelo contrário, está mais preocupada com a beleza macia de Dr. Maceu e com a inacessibilidade de Padre Jerônimo. Uma mulher comprometida das primeiras décadas do século XX a manifestar que "a boca de Maceu era tão vermelha e sugestiva, assim entreaberta, que o lembrar-me de fechá-la com um beijo fez-me olvidar todo o resto" $(2019$, p.10) é bastante curioso. No mínimo, indica que o seu sentimento por Roberto não a consumiu tão completamente de imediato - talvez não se trate de um relacionamento pautado na paixão, mas na amenidade, um sentimento inédito para quem oscilou sempre entre a busca intensa pelo gozo e a catalepsia.

\section{O renascimento de Lúcia?}

Normalmente, os relacionamentos amorosos iniciam explosivos, inebriados pela paixão, e tendem a esmorecer com a passagem do tempo e a 
criação de costumes. Desiludida com o matrimônio e desesperada por novas sensações, Lúcia parece construir uma relação com Roberto que vai do desprezo ao sentimento fraternal, sem nunca passar pela paixão. Estranhamente, apesar do comportamento excessivamente autoritário de seu parceiro, cujo aceite contraria toda a sua autobiografia, Lúcia submete-se em prol da satisfação de outros interesses seus. Tendo experimentado quase tudo o que uma mulher poderia, é chegada a hora do inédito: a experiência de uma mulher burguesa convencional. O sucesso de Lúcia, agora, será o sucesso de sua personagem, o que lhe causa muita satisfação:

\begin{abstract}
Eu sou a enfermeira, a doce e ardente enfermeira que sente a sua vida suspensa e dependente da do seu enfermo adorado!

$\mathrm{O}$ dr. Armando disse-me hoje: "Que devotada criatura a dona Lúcia tem sido!". E nunca eu saboreei tanto um elogio como este que o médico me serviu! (2019, p.136)
\end{abstract}

Diante de seus relatos anteriores, parece descabido tal orgulho de Lúcia em interromper a própria vida e "depender" de um homem doente. O seu orgulho, na verdade, reside na obra de arte que se tornou.

Roberto Toledo é um homem sem biografia escolhido para interpretar uma personagem primordial no romance burguês de Lúcia - o marido protetor e carinhoso. O caráter autoritário de Roberto, não à toa, é incessantemente reforçado. A mulher não precisa de nada além de sua figura, o que torna as amigas, tão presentes outrora, absolutamente dispensáveis. Nada disso ocorre por ignorância:

\footnotetext{
...eu ouvia a promessa de que ele me curaria da moléstia sensual e tremenda que é a enervação, ou a procura exaustiva atrás da felicidade dos sentidos e dos nervos.

Pela primeira vez compreendi o que era o amor entre um homem e uma mulher.

Nas ruas, o ruído aumentara, os fonfons dos automóveis estrilavam no silêncio da noite, enquanto eu, pequena e vencida, entregava-me a Roberto como uma petite chose bem dele e só dele. $(2019, p .116)$
}

A promessa de curar "a procura exaustiva atrás da felicidade dos sentidos e dos nervos" é um tanto quanto incoerente dentro uma relação amorosa. O amor 
entre um homem e uma mulher, portanto, poderia somente se construir em uma neutralidade absoluta, por mera conveniência. Não à toa esta lição é sucedida pelo juízo de Lúcia em ser uma petite chose entregue e vencida, como um animal domesticado. A repetição contínua deste tipo de ponderações nos impede de considerá-las pelo prisma da inocência da mulher apaixonada. Dotada de consciência, Lúcia, de forma quase aristocrática, relaciona-se para alcançar um objetivo distinto da felicidade e do amor, seja ele o suprimento de sua solidão, o desejo de mesclar-se na sociedade da época ou o cumprimento da função essencial feminina, a maternidade. O que importa é que, nesta parte da obra, tudo é deliberado e Lúcia jamais se dá por vencida.

Se no início o desprezo por Roberto não consegue ser plenamente disfarçado, ao fim ela já consegue dizer que o ama - a personagem apodera-se cada vez mais do sujeito. A cena final em que descobre que Júlio ainda está vivo e que, portanto, não pode se casar, denuncia a pouca sinceridade que há na personagem, sempre se moldando às circunstancias: "Afinal, matrimonio é uma velha palavra que, contendo um símbolo de eternidade como a morte, recebe dela um tom negro e sinistro que me apavora. Já me casei uma vez e verifiquei que o casamento, sem o amor e o respeito, não passa de uma farsa grotesca ou trágica" (2019, p.151). Lúcia manifestava o desejo de casar quando acreditava poder, mas não podendo, finge não querer. Ou está sendo sincera agora e fingiu querer anteriormente? Ademais, se somente os casamentos sem amor e respeito não passam de uma farsa grotesca, por que seria este um argumento válido para a não oficialização de seu perfeito relacionamento? Simplesmente porque estamos diante de outra farsa.

É deveras marcado o contraste entre as duas parte da obra. Se na primeira parte Lúcia observa o seu ventre perfeito e jura mantê-lo para sempre assim, longe das máculas maternas (2019, p.27), ao fim de seu diário comemorará a sua gravidez. Curioso, entretanto, é o modo com que o faz: "amo esse sofrimento que resgatará a minha existência passada e dará à luz do mundo um ente saído das minhas entranhas e concebido entre dores e gemidos" (2019, p.149). Ter um filho seria outro sacrifício necessário para mergulhar completamente em seu projeto, um segundo redentor. Orgulhosas mães não tendem a pensar no exercício de sua função essencial pelo prisma das dores e 
gemidos provocados pelo esgarçamento de suas entranhas - Lúcia diz exatamente o oposto que do que escreve, como o fará muitas vezes mais:

\begin{abstract}
O meu ceticismo, o meu sarcasmo, tinham sido vencidos pela afeição desse homem grande, bom e dedicado. Adorei Roberto, vivi extasiada nos seus braços, submissa à sua vontade, numa languidez de sultana favorita, numa devoção de beata. Ele mostrava-se encantado, fazendo projetos, ditando ordens, no seu papel de macho vencedor de fêmea. $E$ eu obedecia-lhe sempre, radiosa de ser obrigada a satisfazer-lhe os desejos, a dobrar-me aos seus decretos, a curvar-me diante de sua soberania. (2019, p.117)
\end{abstract}

Eis uma descrição muito inquietante para um relacionamento com um homem "bom e dedicado", sobretudo quando a primeira parte da obra (e inclusive o seu próprio nome) ilustra com maestria a lucidez da personagem. Certamente, o seu sarcasmo não foi vencido.

\title{
Considerações finais
}

Rápidas buscas sobre Mme. Chrysanthème na internet levam-nos a crer que estamos diante de uma escritora deliberadamente feminista. Isto não é uma verdade absoluta - suas publicações jornalísticas situam-na como uma mulher muito crítica em relação à importação equivocada do movimento. Entretanto, críticos como Humberto de Campos qualificaram-na como uma escritora que dissemina o ódio aos homens ${ }^{5}$ ao buscar alertar suas semelhantes por meio da literatura. Se estes dados não nos encaminham para uma conclusão, ao menos reforçam que $o$ ato de criar de uma transgressora personagem feminina a ser salva e fecundada pelo homem redentor é, no mínimo, muito estranho e incompatível com o resto de sua produção ficcional.

Em Enervadas, testemunhamos a aproximação de dois gêneros muito particulares, a autobiografia e o diário. Se a autobiografia já pressupõe alguma fiç̧ão, o mesmo não ocorre tão explicitamente com o diário. Todavia, Lúcia radicaliza a proporção entre realidade e fiç̧ão, tornando-se uma personagem duplamente ficcional, criada por Chrysanthème e posteriormente por si mesma. Não seríamos capazes aqui de elaborar uma conclusão acerca das intenções

\footnotetext{
${ }^{5}$ Correio da manhã, 20 fev. de 1929.
} 
desta personagem tão pouco confiável, mas algumas provocações devem ser feitas.

Segundo Lejeune (2008, p.262), um diário sempre pressupõe um apelo a um leitor futuro e sempre resulta em uma contribuição à memória coletiva, exceto quando o diarista possui a coragem suficiente para destruí-lo. Lúcia manifesta claramente o desejo de ser lida pela posteridade, forjando a memória que restará de si. Podemos pensar que sua escrita quis ilustrar a sua capacidade de sentir alguma coisa, buscando superar o destino da mulher fatal - a busca pelo incessante pelo gozo que não pode ser jamais satisfeito (DOTTIN-ORSINI, 1996). Ela não pôde fugir dele, mas pôde fingir que sim, agindo à serviço da burguesia para dela debochar.

É ainda relevante o seu amor artificialmente concebido pelo homem que a submete, evidenciando o ridículo da pacata vida de classe-média brasileira. A obra encerra-se com a eloquente expressão "je m'en fiche", mais ampla do que aparenta ser: Lúcia não se importa não apenas com a sua união burguesa frustrada, mas também com a sua existência num sentido lato. É uma alegoria de sua experiência profundamente entediada, num movimento de eterna busca que poderia obter sucesso somente na ficção.

\section{Referências bibliográficas}

BAUDELAIRE, Charles. "O pintor da vida moderna". In: Poesia e Prosa. Rio de Janeiro: Nova Aguilar, 2006.

CARVALHO, Elysio de. "Os morfinômanos". In: Escritos policiais. Rio de Janeiro: FAPERJ, 2017.

CHRYSANTHÈME. Enervadas. São Paulo: Carambaia, 2019.

DOTTIN-ORSINI, Mireille. A mulher que eles chamavam fatal: textos e imagens da misoginia fin-de-siècle. Rio de Janeiro: Rocco, 1996.

GENS, Rosa. "Cecília Vasconcelos e as modernas mulheres: a figuração de Chrysanthème" In: XV ABRALIC, 2016, Rio de Janeiro, Anais Eletrônicos... Rio de Janeiro: Dialogarts, 2016. pp. 1112-1119.

JOZEF, Bella. "(Auto)biografia: os territories da memória e da história". In: AGUIAR, Flávio et al. Gêneros de fronteira: cruzamentos entre o histórico e o literário. São Paulo: Xamã, 1997. pp. 217-225. 
LEJEUNE, Philippe. O pacto autobiográfico: de Rousseau à internet. Belo Horizonte: Editora UFMG, 2008.

LODGE, David. "The unreliable narrator". In: The art of fiction: illustrated from classic and modern texts. Nova lorque: Viking Penguin, 1993.

LOTI, Pierre. Madame Chrysanthème. Nova lorque: Current Literature Publishing Company, 1908.

PINTO, Maria de Lourdes de Melo. Memória de autoria feminina nas primeiras décadas do século $X X$ : a emergência da obra periodística de Chrysanthème. Tese (Doutodado em Letras) - Faculdade de Letras, Universidade Federal do Rio de Janeiro. Rio de Janeiro, 2006.

REIS, Carlos; LOPES, Ana Cristina M. Dicionário de Teoria da Narrativa. São Paulo: Editora Ática, 1988. 